\title{
Review on Effect of Fruit Load on Dry Matter Production and Partitioning in Crops
}

\author{
Abebe Assefa ${ }^{1,2 *}$, Adugna Debella ${ }^{2}$ \\ ${ }^{1}$ Wochamo University College of Agricultural Science, Hossana, Ethiopia \\ ${ }^{2}$ Hawassa university, College of Agriculture, School of Plant and Horticultural Sciences, Ethiopia \\ *Corresponding Author: Abebe Assefa, Jimma 1Wochamo University College of Agricultural Science, \\ Hossana, Ethiopia
}

\begin{abstract}
The fruit load has a large effect on dry matter production and partitioning. The fruit is the main organ of the "sink", and there is competition for nutrients in the growth and development process. Excessive amount of fruits per tree decrease fruit size and quality, consume tree reserves and reduce cold hardiness. The proper fruit thinning can improve the average weight of fruit, improve the fruit quality and fruit commodity rate Meanwhile, the proper crop load can be conducive for improving the leaf photosynthesis leads to increased dry matter production. The decline of crop load can significantly increase the leaf area, and the total nitrogen content of leaves so as to improve the leaf Photosthetnic and delay leaf senescence, that increasing dry matter production and decreasing dry matter partitioning. Stem, trunk and root growth decrease almost linearly with crop load, while dry matter allocation relatively to leave to shoot ratio. Increase in fruit firmness with decreasing crop load is not well understood but could be related to the increase of soluble solids and dry matter. An increase in fruit firmness with lower crop loads. The decrease in dry-matter percentage of the fruits was also partly the result of the increased growing period of individual fruits, because the dry matter percentage of fruit decrease at increasing in fruit load. Generally, from this review of literature we can conclude that controlling fruit load effectively regulated the distribution of assimilate for growth, development and overall life cycle of plant.
\end{abstract}

Keywords: fruit load, dry matter production, dry matter partitioning

\section{INTRODUCTION}

In fruit trees such as apple (Palmer 1992), peach (Génard et al. 1998) and coffee (Kumar and Tieszen 1976, Cannell 1985), fruit load has a large effect on dry matter production and partitioning.

According to the characteristics of the output and input of plant photosynthetic products, the tissues and organs can be divided into two categories, namely "sink" and "source". The "source" refers to the organs responsible for the production and transportation of nutrients to other organs, mainly designating the blade. The "sink" refers to the organs consuming or reserving nutrients, such as young leaves, stems, roots, flowers, fruit, seeds, etc. For fruit trees, the fruit is the main organ of the "sink", and there is competition for nutrients in the growth and development process. Excessive amount of fruits per tree decrease fruit size and quality, consume tree reserves and reduce cold hardiness (Dennis, 2000). Only the balanced distribution of assimilation products in the organs of sink and source can guarantee the high economic yield. Therefore, it is of great significance to adjust the "sink-source" relationship in fruit trees for the growth and development of fruit, fruit quality and storage nutrition. The crop load is one of the most important factors influencing the relationship of sink (fruit)-source (leaf) of fruit trees. With inappropriate crop load, the photosynthesis and storage nutrient of fruit trees were adversely influenced, which resulted in the phenomenon of biennial bearing for continuous years (Peng,2003 and Krasniqu,2013). Smitha and Samach,2013 found that high crop load of fruit trees led to the weakness of tree vigor and affected the development of leaves which resulted in the fruit trees' senescence at later growth stage (Urba,2009 and Chois,2016). Additionally, high crop load reduced trees storage nutrition, which significantly affected the vegetative growth and flower bud differentiation in the second year (Monselise and Lenz, 1980)

High fruit load decreases shoot growth and results in strong alternate bearing and production patterns in coffee. Furthermore, branch dieback is often observed at high fruit load as a result of the high carbon 
demand of coffee berries, which represents up to $60 \%$ of carbohydrate production over the annual cycle (Cannell 1971a). At high fruit loads, there is competition for carbohydrates among berries that strongly affects coffee bean size, biochemical composition and beverage quality (Vaast et al. 2005). Cannell $(1971 b)$ demonstrated that the presence of coffee berries increased total branch dry matter gain and speculated that berries stimulated leaf net photosynthesis $(P \mathrm{n})$. As documented in orange (Moreshet and Green 1980), avocado (Blanke 1992) and peach (Pavel and DeJong 1993a), there is evidence that green fruits are photosynthetically active and can contribute to their own carbohydrate requirements for growth and maintenance. Cannell (1971b) indirectly demonstrated that immature, green coffee berries could contribute to their own carbohydrate needs. However, there are no published data on coffee berry $\mathrm{CO} 2$ exchange rates and the contribution of berry photosynthesis to the carbohydrate requirements of the developing fruit. Leaf $\mathrm{Pn}$ increases in response to increasing fruit load when carbohydrate accumulation in the fruit is high in peach (DeJong 1986) and apple (Palmer 1997), and maximum leaf $P \mathrm{n}$ of peach is strongly related to leaf:fruit ratio and fruit carbohydrate demand (Ben Mimoun et al. 1996). However, several authors have observed feedback inhibition of leaf $P \mathrm{n}$ in response to the accumulation of leaf reserves (Guinn and Mauney 1980, Foyer 1998). Cannell (1971b) documented that large, long-distance carbohydrate transfers occur in coffee trees. The rest of the tree generally buffers the fruit load effect on fruit-bearing branch development by acting either as a source or a sink (Ben Mimoun et al. 1998). To study the effect of assimilate partitioning between the tree and individual branches, carbohydrate transfer can be altered by branch ring-barking (Dann et al. 1984). In response to this treatment, branches usually support increased fruit growth with reduced vegetative growth as shown in peach (Dann et al. 1984) and apple (Schechter et al. 1994). Branch ring-barking can also alter leaf characteristics by increasing leaf mass ratio and decreasing leaf $P$ n (Schechter et al. 1994). Fruit thinning is effective in managing the relationship between vegetative and reproductive growth, which ensures high quality and yield in fruit trees by adjusting the relationship between "sink" and "source" and changing the transportation and distribution of photosynthate (Morandi and Grappadelli,2009, Seehuber,2011). Fruit thinning has been shown successfully to overcome alternate bearing, increase nutrient accumulation, and prevent premature aging (Hehnen,2012). And, numerous researches have demonstrated that the proper fruit thinning can improve the average weight of fruit, improve the fruit quality and fruit commodity rate (Bussi,2005 and Serra,2016). Meanwhile, the proper crop load can be conducive for improving the leaf photosynthesis (Syvertsen,2003 and Kassai,2008). The reasonable crop load is a crucial factor of guaranteeing the tree's growth to gain the high yield, stable production and good quality (Biserka,2012 and Giedre,2016). However, the tree's growth and its yield are closely related to the nutrient distribution of carbon and nitrogen. The carbon nutrition directly afects the growth and structure of trees, and the output and quality of fruits (Giulian,1997 and Goldschmidt,19990). As the essential mineral element of fruit trees, nitrogen is closely related to quality, particularly fruit size and color. Carbon and nitrogen metabolism are the most important metabolic pathways in plants, which is intimately related with each other (Wargo,2003). The nitrogen metabolism provides enzymes and photosynthetic pigments for the carbon metabolism. The suitable nitrogen nutrition effectively improves the leaf photosynthesis and the chlorophyll. The photosynthetic rate in per unit area increased with the increase of nitrogen content, but the assimilation rate of plants decreased when the nitrogen reached to a certain value (Wango,2013).

Similarly, the aboveground growth of plants can promote the absorption of nitrogen in roots. Under insufcient illumination, the activity of roots is reduced, afecting the absorption of nitrogen and the photosynthesis of leaves (Silva,2012). Thus, coordinating the reasonable distribution of carbon and nitrogen in plants is of great significance to improve their dry matter production and partition .The objective of the article is to review the effect of fruit or crop load on dry matter production and portioning of crop.

\section{LITERATURE REVIEW}

\subsection{Leaf Area, Chlorophyll and Photosynthetic Rate}

As Ling peng et. al, (2017) indicated that Low-crop load treatments were significantly higher compared with the . High-crop load treatment, among which the Low-crop load treatment was the highest at the fruit maturity stage in both years (Table 1). The total nitrogen content of leaves in the Medium and Low-crop load larger than that of the High-crop load treatment respectively The root-shoot ratio was significantly affected by fruit crop load under the same nitrogen level, which gradually increased with fruit crop load decreasing. As Sharples (1968) studied Compared with the High-crop load treatment, 
the root shoot ratio in Medium and Low-crop load treatments increased. The results done by Plamer et.al, (1997) suggested that the decline of crop load can significantly increase the leaf area, and the total nitrogen content of leaves so as to improve the leaf Photosthetnic and delay leaf senescence. Meanwhile, the decline of crop load can significantly increase the root-shoot ratio. Lenz (1986) reported significantly greater leaf areas on non fruiting than fruiting trees

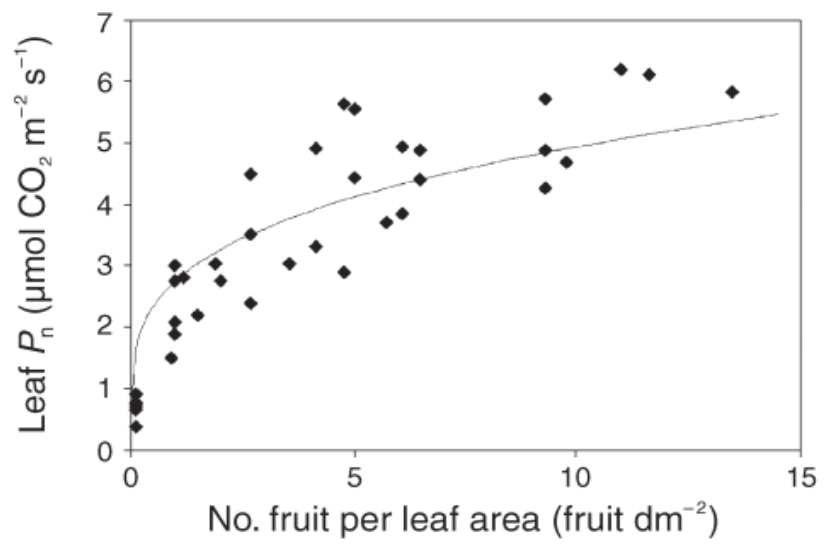

Fig1. Effect of fruit load on net leaf assimilation rate

The leaf is the main organ of photosynthesis to produce the dry matter, and the chlorophyll is the main chemical compounds with nitrogen (Jifton,2005 and Boussodia,2010). The increasing leaf area and chlorophyll content in the late growth stage are propitious to improve photosynthesis and delay leaf senescence (Silva,2012 and Anglelis,2012). Nii (1997) suggested that increasing crop load resulted in a decrease in leaf area, dry mass of each unit leaf area, and an increase in chlorophyll content. Wunsche et al. (2005) also pointed out that increased crop load could increase chlorophyll concentration. The study done by Ling peng et. al, (2017), the leaf area on Medium and Low-crop load treatments were significantly higher than that of High-crop load treatment, which was consistent with the above results, but the leaf chlorophyll content and photosynthetic rate reduced with the increase of fruit crop load . The reason is that the competition for the photosynthetic nutrient in the late development stage of fruit exists between shoots and roots, and the photosynthetic products are mainly transported to the "sink" organ (fruit) with the increasing crop load (Lu,2002).

Jens and John (2000) indicated at the early growth stage, trees with reduced crop loads must have partitioned proportionally larger amounts of photosynthesis into these alternative vegetative sinks, which in turn could utilize the extra carbohydrate. In apple, fruiting reduced leaf weight and leaf area but result in greater seasonal dry matter accumulation compared to non fruiting trees, suggesting a greater photosynthetic efficiency (Plammer,1992)

Thus, the roots will appear "hunger" due to the insufficient organic nutrient (Mimom and Dejong, 2006), inhibiting the absorption of mineral nutrition and water. This phenomenon will lead to the decrease of the nutrient level in the leaves that might be the main cause of decrease of photosynthetic rate (Yeman and Shibayam,2006). In addition, as the Ling peng et. al, (2017) studied the nutrient content of leaves at later growth stage showed that the total nitrogen content in the leaves with the Medium and Low-crop load treatments was significantly higher than that of High-crop load treatment , which also showed that thinning fruit could significantly improve the nitrogen content of leaves, so as to increase the chlorophyll content of leaves. The linear relationship between leaf photosynthesis and photochemical yield confirms that the reduction in photosynthesis in relation to different crop loads was related to a lowered photochemical efficiency (Edwards and Baker, 1993). The results also suggest that, as the demand for photosynthetic was lowered, the leaves were protected fully by the increased capacity for thermal dissipation (Osmond, 1994).

Table1. Effect of fruit load on starch concentration of bourse shoots leaves

\begin{tabular}{|c|c|c|c|}
\hline Fruit load & $\begin{array}{c}\text { Starch/leaf dry wt } \\
\left(\mathrm{Mg} \mathrm{S}^{-1}\right.\end{array}$ & $\begin{array}{c}\text { Leaf mass/leaf area } \\
\left(\mathrm{Mg} \mathrm{CM}^{-1}\right.\end{array}$ & $\begin{array}{c}\text { Starch /leaf area } \\
\left(\mathrm{Mg.CM}^{-2}\right.\end{array}$ \\
\hline High & 19 & 10.3 & 0.2 \\
\hline Medium & 41 & 11.0 & 0.45 \\
\hline Low & 67 & 11.7 & 0.78 \\
\hline
\end{tabular}




\begin{tabular}{|c|c|c|c|}
\hline None & 80 & 12.5 & 1.01 \\
\hline LSD (0.05) & 17.4 & 0.86 & 0.24 \\
\hline Linear strand & $* * *$ & $* * *$ & $* * *$ \\
\hline
\end{tabular}

Table2. Effect of crop load on various fruit quality parameters

\begin{tabular}{|c|c|c|c|c|c|}
\hline $\begin{array}{l}\text { Crop } \\
\text { load }\end{array}$ & $\begin{array}{l}\text { Background } \\
\text { color (score) }{ }^{2}\end{array}$ & $\begin{array}{c}\text { Soluble } \\
\text { solids (\%) }\end{array}$ & $\begin{array}{c}\text { Starch-iodine } \\
\text { (score) }\end{array}$ & $\begin{array}{c}\text { Firmness } \\
(\mathrm{kg})\end{array}$ & $\begin{array}{c}\text { Dry matter } \\
(\%)\end{array}$ \\
\hline High & 4.6 & 11.6 & 1.7 & 8.4 & 14.3 \\
\hline Medium & 6.2 & 13.3 & 2.8 & 9.5 & 16.6 \\
\hline Low & 6.7 & 14.3 & 3.3 & 10.0 & 17.8 \\
\hline $\operatorname{LSD}_{(0.05)}$ & 1.8 & 2.0 & 1.8 & 1.4 & 2.4 \\
\hline Linear trend & $* * *$ & $* * *$ & $* * *$ & $* * *$ & $* * *$ \\
\hline
\end{tabular}

\subsection{Root and Shoot Growth}

As Gugliuzza et.al,(2002) studied fruit load reduced plant vigor and the rootstock infuluned the extent to which vegetative and root growth were inhibited but not the canopy vs root dry matter partitioning . Stem, trunk and root growth decrease almost linearly with crop load, while dry matter allocation relatively to leave to shoot ratio. As indicated by Lentz (1986) for apple trees, the cumulative effect of two consecutive years of heavy crop loads caused reduction of entire dry matter accumulation. Pace et.al., (2000) found a clear effect of cumulative crop load on dry matter accumulation in all plant components from leaves to root. As Jens and John (2000) indicated due to a compensatory response of trees with lower fruit numbers resulting in increased shoot number, shoot length and hence leaf area. Vigorous root stock reduced the dry matter partitioned to the peach fruit (Caruso et al.,1997) and affect the dry matter partitioning into above or below ground components in apple, while root restriction reduced canopy growth with no alteration of dry matter partitioning.

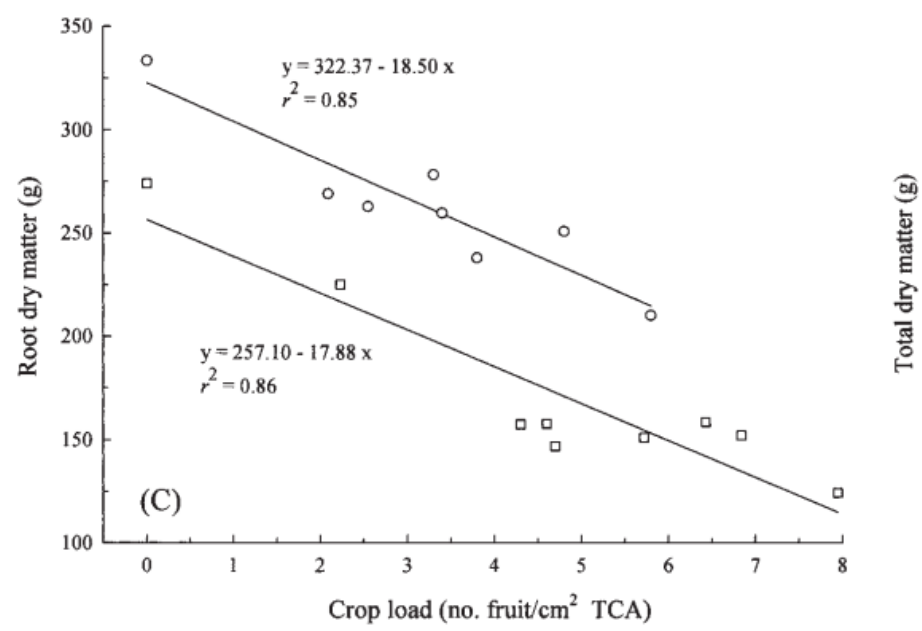

Fig2. Relationship crop or fruit load on root dry matter production

Philippe et.al.(2005) highlight on their finding that shoot growth and berry drop were mainly affected during the last third of the production cycle, which corresponds to the time of bean-filling (Cannell 1985). They observed that reduced shoot growth and high branch dieback in response to high fruit load (Table 2). Wormer and Ebagole (1966) and Cannell (1985) associated these phenomena with the high carbohydrate demand of berries and the depletion of reserves, notably starch, in coffee storage organs (branch, stem and thick roots). Because carbohydrates were preferentially allocated to berries, to the detriment of young apical vegetative branch parts that determine the production level in the following year, the results provide a clear explanation of the strong bi-annual production pattern that has been observed in this highly productive cultivar (Vaast et al. 2005).

\subsection{Plant Growth and Biomass Allocation}

As Marcelis (1994) studied the increasing the number of fruits per plant strongly enhanced the biomass (fresh and dry weight) allocation to the fruits at the expense of the vegetative organs. Dailynondestructive measurements of total plant (excluding the roots) and fruit growth revealed saturation type 
relationship between the daily dry matter distribution toward the fruits and the fruit load expressed as the total dry weight of fruits on a plant. The underlying principles for the increase in fruit firmness with decreasing crop load is not well understood but could be related to the increase of soluble solids and dry matter. A increase in fruit firmness and increase total dry matter with lower crop loads has also been reported by Opara et al. (1997)

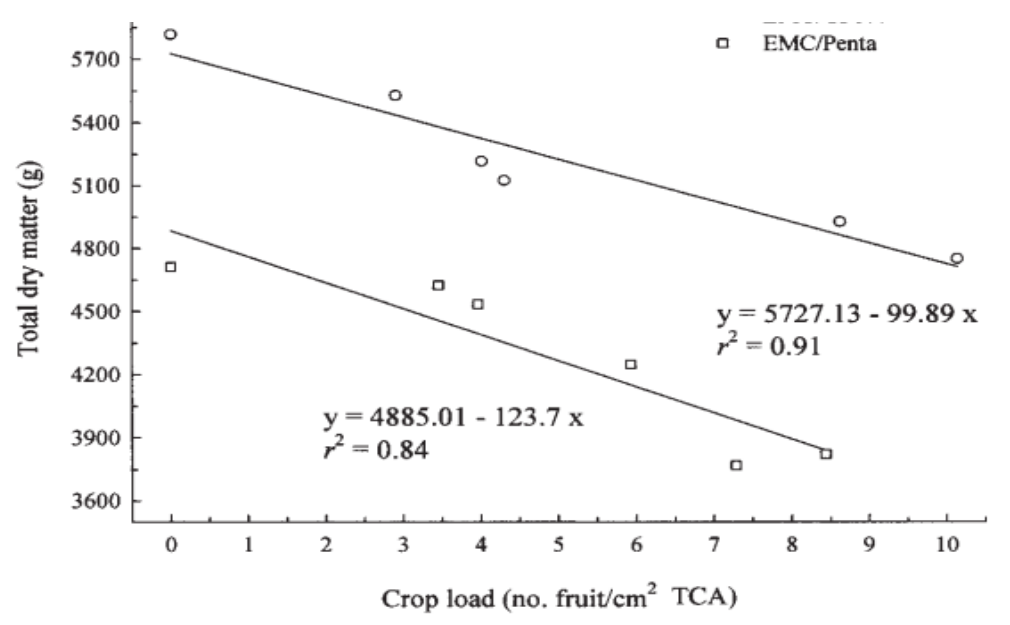

Fig3. Relationship between total dry matter and fruit load

In accordance with Ramirezetal. (1988a) increasing the number of cucumber fruits perplant did not affect total plant dry weight growth but enhanced fruit growth at the expense of vegetative growth. This has also been found in pepper, eggplant and citrus (Hall 1977;Lenz 1979;Nielsen \&Veierskov 1988). The increase in fruit production per plant was less than proportional to the increase in number of fruits retained per leaf axil, because the average growth rates of individual fruits decreased. Moreover, the increase in average number of fruits on a plant was less than proportional to the increase in number of fruits retained per leaf axil because of a decrease in leaf formation rate and an increase in fruit abortion rate . Starck et al. (1979) found an increase in dry-matter percentage of the stem and petioles after removal of flowers in tomato, but Hall \& Milthorpe (1978) found no effect of fruit removal on drymatter percentage of leaves in pepper while the content of polysaccharides increased. As schecther et.al,(1994) indicated because carbohydrates were preferentially allocated to berries, to the detriment of young apical vegetative branch parts that determine the production level in the following year, the finding provide a clear explanation of the strong bi-annual production pattern that has been observed in this highly productive cultivar (Vaast et al. 2005). The research done on coffee by Philipe et.al,(2005) indicate that there was competition for carbohydrates among berries at high fruit loads resulting in reduced individual berry mass and hence bean size - the most important criterion on which coffee quality and price are assessed. The highest individual berry mass was produced on ring-barked branches with $25 \%$ of the initial fruit load that had an initial minimum of $15 \mathrm{~cm} 2$ leaf area per berry and one of $20 \mathrm{~cm} 2$ per berry at the bean-filling stage

\subsection{Growth of Individual Fruit}

As Philippe et al,(2005) indicated the average growth rate of individual fruit decreased with increasing number of fruits per plant. With increasing fruit number both the length and circumference of the harvested fruits decreased, while the ratio of length to circumference decreased (Marcelis1994) The dry-matter percentage of both the fruits and the vegetative plant parts decreased when the number of fruits increased (Table 5) The increase in total plant fresh weight production with increasing number of fruits was accompanied by a decrease in the dry matter percentage of the plants, while dry matter production was not affected. The decrease in dry-matter percentage of both the fruits and vegetative parts at increasing number of fruits might indicate a decrease in the level of assimilate reserves in the plants. The decrease in dry-matter percentage of the fruits was also partly the result of the increased growing period of individual fruits, because the dry matter percentage of fruit decrease at increasing fruit age

\subsection{Nitrogen and Carbon Partitioning Rate}

Ling peng et. al, (2017) indicated the percentage of Nitrogen in each organ accounted for the total Nitrogen content in all organs reflected the distribution of nitrogen fertilizer in the trees and the 
migration regularity in organs. As he stated Nitrogen on High-crop load treatment mainly distributed into the fruit at the fruit maturity stage in both years, and it was followed by roots, leaves, branches and other organs. Biserka, M. et al (2012) founded that with the reduction of crop load, the distribution rate of Nitrogen in fruits gradually decreased but it increased in the roots, leaves, annual branches and other organs. The results indicated that the distribution content of nitrogen, which was absorbed by the plant to the reproductive organs, reduced with the decrease of crop load, but its distribution to other organs increased, thereby increasing the storage of the tree nutrition.

As Jens and Jons, 2000 studied the proportion of Carbon assimilates assigned to each organ is related to its competitive ability, which referred to the ability of absorbing Carbon from the labeled leaves in the active parts of metabolism and growth. It was supported by Ling peng et. al, (2017) Carbon in highcrop load treatment was mainly distributed in the fruits at the fruit maturity stage in both years, and followed by roots, leaves, branches and other organs. With the decrease of crop load, the distribution rate of Carbon in the fruits gradually reduced, but increased in roots, leaves, annual branches and other organs. The work done by Philippe et,al,2005 showed that the transportation and distribution of carbohydrates to the fruits decreased but the distribution to the roots, leaves, annual branches and other organs increased with the decrease of crop load, so as to promote the plant vegetative growth. The finding also supported by Ling peng et. al, (2017) sated that the distribution rate of Carbon and Nitrogen reproductive organs' (fruits) ability of competition for Carbon and Nitrogen was the strongest at the fruit maturity stage.

However, Ling peng et. al, (2017) founded in his research the content of Carbon and Nitrogen allocating to the reproductive organs gradually decreased with the decline of the crop load, but the content allocating to the vegetative organs (annual branches and leaves) and storage organs (roots and perennial branches) increased, so as to promote the vegetative growth and increase the storage nutrition of the trees. It was also proved by Jens and Johns, 2000 the higher total nitrogen content in nutrient organs (annual branches and leaves) and storage organs (roots) on Medium and Low-crop load treatments than that of High crop load treatment. Thus, the appropriate fruit thinning reduced the consumption of carbon and nitrogen nutrient, promoted the current vegetative growth and also increased the reserve of carbon and nitrogen in the vegetative organs. This was conducive to the supply of plant's growth in the spring of the next year and laid the foundation for next year's harvest. Solomakhin and Blanke (2010) showed that thinning fruit could increase the mean fruit weight and improve fruit quality. Gofnet (1995) believed that the thinning fruit could stimulate fruit enlargement, and the increasing size of fruit was related to the promotion of cell division and expansion at the same time and the increasing amount and size of cells (Njoroge, \& Reighard, 2008). However, in the production, orchard owners have focused on yield and ignored quality by little or no fruit thinning, thereby resulting in the decrease of the proportion of good quality fruits. The study done by Ling peng et. al, (2017) showed that the Medium and Low-crop load treatments significantly improved the fruit quality. These results are similar to those previously observed (Giedre, S. et al 20016,, Castro, 2015) showing improved apple quality in terms of each fruit weight, size, and frmness with a decrease in crop load of each tree (Seehuber, 2011, Giedre, 2016 and Schmidt,2011). The significant increase in the rate of good quality fruit resulted in overall economic benefits. Economic benefits in the fruit industry were mainly determined by the cost of production, fruit yield and quality, as well as other determinants (Iglesias, 2008).

\section{SUMMARY AND CONCLUSION}

The fruit load has a large effect on dry matter production and partitioning. The fruit is the main organ of the "sink", and there is competition for nutrients in the growth and development process. Excessive amount of fruits per tree decrease fruit size and quality, consume tree reserves and reduce cold hardiness. The high crop load of fruit trees led to the weakness of tree vigor and affected the development of leaves which resulted in the fruit trees' senescence at later growth stage in additionally, high crop load reduced trees storage nutrition, which significantly affected the vegetative growth and flower bud differentiation. The proper fruit thinning can improve the average weight of fruit, improve the fruit quality and fruit commodity rate Meanwhile, the proper crop load can be conducive for improving the leaf photosynthesis leads to increased dry matter production. The decline of crop load can significantly increase the leaf area, and the total nitrogen content of leaves so as to improve the leaf Photosthetnic and delay leaf senescence, that increasing dry matter production and decreasing dry matter partitioning . The leaf chlorophyll content and photosynthetic rate reduced with the increase of fruit crop load. The reason is that the competition for the photosynthetic nutrient in the late development 
stage of fruit exists between shoots and roots, and the photosynthetic products are mainly transported to the "sink" organ (fruit) with the increasing crop load. Stem, trunk and root growth decrease almost linearly with crop load, while dry matter allocation relatively to leave to shoot ratio. The compensatory response of trees with lower fruit numbers resulting in increased shoot number, shoot length and hence leaf area that .vigorous root stock reduced the dry matter partitioned. The increase in fruit firmness with decreasing crop load is not well understood but could be related to the increase of soluble solids and dry matter. An increase in fruit firmness with lower crop loads. The decrease in dry-matter percentage of the fruits was also partly the result of the increased growing period of individual fruits, because the dry matter percentages of fruit decrease at increasing. The transportation and distribution of carbohydrates to the fruits decreased but the distribution to the roots, leaves, annual branches and other organs increased with the decrease of crop load, so as to promote the plant vegetative growth. Generally, from this review of literature we can conclude that controlling fruit load effectively regulated the distribution of assimilate for growth, development and overall life cycle of plant.

\section{REFERENCES}

[1] Angelis, V.D. 2012. Nitrogen application in autumn delayed leaf senescence in apple (Malus domestica Borkh.). Ria Revista De Investigaciones Agropecuarias 55-62

[2] Blanke, M.M. 1992. Photosynthesis of avocado fruit. In Proc. Second World Avocado Congress, Vol. 1. Eds. C. Lovatt, P.A. Holthe and M.L. Arpaia. University of California, Riverside, CA, pp 179-189.

[3] Ben Mimoun, M., J.J. Longuenesse and M. Génard. 1996. Pmax as related to leaf : fruit ratio and fruit assimilate demand in peach.J. Hortic. Sci. 71:767-775

[4] Ben Mimoun, M., M. Génard and J. Besset. 1998. Relationships between shoots and the rest of the tree: effect on fruit growth. Acta Hortic. 465:303-308

[5] Biserka, M. 2012. Nitrogen fertilization and chemical thinning with 6-benzyladenine afect fruit set and quality of golden delicious apples. Scientia Horticulturae 140(6), 81-86

[6] Bussi, C. 2005. Pruning intensity and fruit load infuence vegetative and fruit growth in an early-maturing peach tree (cv. Alexandra). Fruits 60(2), 133-142

[7] Boussadia, O. 2010. Efects of nitrogen defciency on leaf photosynthesis, carbohydrate status and biomass production in two olive cultivars 'Meski' and 'Koroneiki. Scientia Horticulturae 123(3), 336-342

[8] Cannell, M.G.R. 1985. Physiology of the coffee crop. In Coffee: Botany, Biochemistry and Production of Beans and Beverage. Eds. N.M. Clifford and K.C. Willson. Croom Helm, London, pp 108-134.

[9] Cannell, M.G.R. 1971a. Effects of fruiting, defoliation and ring-barking on the accumulation of dry matter in branches of Coffea arabica L. in Kenya. Exp. Agric. 7:63-74

[10] Cannell, M.G.R. 1971b. Production and distribution of dry matter in trees of Coffea arabica L. in Kenya as affected by seasonal climatic differences and the presence of fruit. Ann. Appl. Biol. 67:99-120

[11] Castro, D. 2015. Crop-loading studies on 'Caricia' and 'Eva' apples grown in a mild winter area. Sci. Agricola. 72(3), 237-244

[12] Choi, S. T.2016 . Efects of diferent leaf-fruit ratios on uptake and partitioning of N and $\mathrm{K}$ in Uenishiwase' persimmon trees. Scientia Horticulturae 212, 69-73

[13] Dann, I.R., R.A. Wildes and D.J. Chalmers. 1984. Effects of limb girdling on growth and development of competing fruit and vegetative tissues of peach trees. Aust. J. Plant Physiol. 11:49-58

[14] Drake, S. R. et al. 2002). Time of nitrogen application and its infuence on 'golden delicious' apple yield and fruit quality. Journal of PlantNutrition. 25(1), 143-157

[15] DeJong, T.M. 1986. Fruit effects on photosynthesis in Prunus persica. Physiol. Plant. 66:149-153.

[16] Dennis, F. G.2000. The history of fruit thinning. Plant Growth Regul. 31(1), 1-16

[17] Foyer, C.H. 1988. Feedback inhibition of photosynthesis through source-sink regulation in leaves. Physiol. Plant. 26:483-492

[18] Edwards, G.E. and N.R. Baker. 1993. Can CO2 assimilation in maize leaves be predicted accurately from chlorophyll fluorescence analysis? Photosyn. Res. 37:89-102.

[19] Génard, M., F. Lescourret, M. Ben Mimoun, J. Besset and C. Bussi. 1998. A simulation model of growth at the shoot-bearing fruit level. II. Test and effect of source and sink factors in the case of peach. Eur. J. Agric. 9:189-202.

[20] Guinn, G. and J.R. Mauney. 1980. Analysis of CO2 exchange assumptions: feedback control. In Predicting Photosynthesis for Ecosystem Models. Eds. J.D. Jesketh and J.W. Jones. CRC Press, New York, pp 1-16 
[21] Giedre, S. 2016. Relationships between apple tree rootstock, crop-load, plant nutritional status and yield. Scientia Horticulturae 211,167-173 Giuliani, R. et al(1997). Efects of crop load on apple photosynthetic responses and yield. Acta Horticulturae 451, 303-312 (1997)

[22] Goldschmidt, E. E. 1999. Carbohydrate supply as a critical factor forcitrus fruit development and productivity. HortScience 34(6), 1020-1024

[23] Hehnen, D.2012. Mechanical fower thinning improves fruit quality of apples and promotes consistent bearing. Scientia Horticulturae 134, 241-244

[24] Iglesias, I. 2008. Diferences in fruit colour development, anthocyanin content, fruit quality and consumer acceptability of eight 'Gala' apple strains. Scientia Horticulturae 119(1), 32-40

[25] Jifon, J. L. 2005. Growth environment and leaf anatomy afect nondestructive estimates of chlorophyll and nitrogen in Citrus sp. leaves. Journal of the American Society for Horticulturae Science 130(2), 152-158

[26] Lu, Y. H.2002. Input and distribution of photosynthesized carbon in a fooded soil. Global Biogeochem Cycles 16(4), 32-31 (2002)

[27] Jens N. Wünsche1 and John W. Palmer . 2000. Effects of Crop Load on Fruiting and Gas exchange Characteristics of 'Braeburn'/M.26 Apple Trees at Full Canopy. Hort research. Available on line WWW. J. AMER. SOC. HORT. SCI. 125(1):93-99.

[28] Kasai, M .2008. Regulation of leaf photosynthetic rate correlating with leaf carbohydrate status and activation state of Rubisco under avariety of photosynthetic source/sink balances. Physiologia Plantarum 134(1), 216-226

[29] Krasniqi, A. L. 2013. Quantifying keyparameters as elicitors for alternate fruit bearing in cv. 'elstar' apple trees. Plant Sci. 212, 10-14

[30] Kumar, D. and L.T. Tieszen. 1976. Some aspects of photosynthesis and related processes in Coffea arabica L. Kenya Coffee. 41: 309-315

[31] Monselise, S. P. \& Lenz, F. 1980. Efect of fruit load on photosynthetic rates of budded apple trees/Einfuß des fruchtbehanges auf die photosyntheseraten junger, veredelter Apfelbäume. Die Gartenbauwissenschaf 45(5), 220-224

[32] Marcelis L. 1994. Fruit growth and dry matter partitioning in cucumber .wagegenin, Nethrlands Avaliable on line, Thesis result

[33] Moreshet, S. and G.C. Green. 1980. Photosynthesis and diffusion conductance of the Valencia orange fruit under field conditions. J. Exp. Bot. 21:15-27

[34] Morandi, B. \& Grappadelli, L. C. 2009. Source and sink limitations in vascular fows in peach fruit. Journal of Horticultural Science \& Biotechnology 84(1), 150-156

[35] Mimoun, M. B. \& DeJong, T. M .2006. Efect of fruit crop load on peach root growth. VI International Peach Symposium 713, 169-176

[36] Nii, N. 1997. Changes of starch and sorbitol in leaves before and afer removal of fruits from peach trees. Ann. Bot. 79(2), 139-144

[37] Ling P, Ning D, Qian C, Zhanling Z, , Shunfeng G \& Yuanmao Ji. 2017. Efects of crop load on distribution and utilization of $13 \mathrm{C}$ and $15 \mathrm{~N}$ and fruit quality for dwarf apple trees. Scientific report, Abvaliable on line.wwww.nature.com./ Scientific report

[38] Lenz, F. 1986. Fruit effects on transpiration and dry matter production in apples, p. 101-104. In: A.N. Lakso and F. Lenz (eds.). The regulation of photosynthesis in fruit trees. Proc. N.Y. State Agr. Expt. Sta., Geneva. Njoroge, S. M. C. \& Reighard, G. L (2008). Tinning time during stage I and fruit spacing influences fruit size of 'Contender' peach. Scientia Horticulturae 115(4), 352-359)

[39] Osmond, C.B. 1994. What is photoinhibition? Some insights from comparisons of shade and sun plants, $p$. 1-24. In: N.R. Baker and J.R

[40] Opara, L.U., C.J. Studman, and N.H. Banks. 1997. Physico-mechanical properties of 'Gala' apples and stemend splitting as influenced by orchard management practices and harvest data. J. Agr. Eng. Res. 68:139-146

[41] Palmer, J.W., R. Guiliani and H.M. Adams. 1997. Effects of crop load on fruiting and leaf photosynthesis of 'Braeburn'/ M.26 apple trees. Tree Physiol. 17:741-746

[42] Pavel, E.W. and T.M. DeJong. 1993a. Seasonal CO2 exchange patterns of developing peach (Prunus persica) fruits in response to temperature, light and CO2 concentration. Physiol. Plant. 88: 322-330

[43] .Palmer, J.W. 1992. Effects of varying crop load on photosynthesis, dry matter production and partitioning of Crispin/M.27 apple trees. Tree Physiol. 11:19-33

[44] Peng, F. T. 2003. Efect of nitrogen on apple fruit hormone changing trends and development. Plant Nutrition and Fertilizer Science (in Chinese) 9(2), 208-213 
[45] Philippe V, Jobert k, Anicolas F, Jean D and Michel G,2005. Fruit load and branch ring-barking affect carbon allocation and photosynthesis of leaf and fruit of Coffea arabica in the field. Avaliable on line www.Heron Publishing-Victoria, Canada

[46] Schechter, I., J.T.A. Proctor and D.C. Elfving. 1994. Apple fruit removal and limb girdling affect fruit and leaf characteristics. J. Am. Soc. Hortic. Sci. 119:157-162

[47] Smitha, H. M. \& Samac, A .2013. Constraints to obtaining consistent annual yield sin perennial tree crops. I: Heavy fruit load dominates over vegetative growth. Plant Sci. 207(3), 158-167

[48] Seehuber, C. 2011. Regulation of source: sink relationship, fruit set, fruit growth and fruit quality in European plum (Prunus domestica 1.)-using thinning for crop load management. Plant Growth Regul. 65(2), 335-341 (2011)

[49] Schmidt, T. R. 2011 . Crop load management of tree fruits in the pacifc northwest of USA. Acta Hortic. 903, 759-765 (2011)

[50] Serra, S. 2016. Crop load infuences fruit quality, nutritional balance, and return bloom in 'Honeycrisp' apple. HortScience 51(3), 236-244

[51] Sharples, R.O. 1968. Fruit thinning effects on the development and storage quality of 'Cox's Orange Pippin' apple fruits. J. Hort. Sci. 43:359-371

[52] Silva, T. R. B. D .2012. Relationship between chlorophyll meter readings and total N in crambe leaves as affected by nitrogen topdressing. Industrial Crops \& Products 39(1), 135-138

[53] Syvertsen, J. P. 2003 . Fruit load and canopy shading afect leaf characteristics and net gas exchange of 'Spring' navel orange trees. Tree Physiolog 23(13), 899-906

[54] Solomakhin, A. A. \& Blanke, M. M. 2010. Mechanical fower thinning improves the fruit quality of apples. J. Sci. Food Agric. 90(5),735-743 (

[55] Urba, L. 2009. Modeling the effects of flowering, drought and fruit load on mango leaf photosynthesis. Eighth International Mango Symposium 820(2), 271-279

[56] Vaast, P., B. Bertrand, B. Guyot, J.J. Perriot and M. Génard. 2005. Fruit thinning and shade improve bean characteristics and beverage quality of coffee (Coffea arabica L.) under optimal conditions.J. Sci. Food Agric. In Press.

[57] Wargo, M. J.2003. Fruit size, yield and market value of 'GoldRush' apple are afected by amount, timing and method of nitrogen fertilization. Hort. Technol. 13(1), 153-16

[58] Wang, H. 2013. Efects of diferent rootstocks on distribution and utilization of $13 \mathrm{C}$ and $15 \mathrm{~N}$ of Malus $\times$ domestica Borkh. 'Red Fuji'. Acta Horticulturae Sinica (in Chinese) 40(4), 733-738

[59] Wünsche, J. N.2005. Physiological and biochemical leaf and tree responses to crop level in apple. Tree Physiol. 25(10), 1253-1263

[60] Wormer, T.M. and H.E. Ebagole. 1965. Visual scoring of starch in Coffea arabica L. II. Starch in bearing and non-bearing branches.Exp. Agric. 1:41-53

[61] Yamane, T. \& Shibayama, K .2006. Efects of trunk girdling and crop load levels on fruit quality and root elongation in 'Aki Queen' grapevines. Engei Gakkai Zasshi. 75(6), 439-444

Citation: Abebe Assefa, Adugna Debella, "Review on Effect of Fruit Load on Dry Matter Production and Partitioning in Crops", International Journal of Forestry and Horticulture, 6(3), pp. 30-38. DOI: https:// doi.org/10.20431/2454-9487.0603004

Copyright: (C) 2020 Authors, this is an open-access article distributed under the terms of the Creative Commons Attribution License, which permits unrestricted use, distribution, and reproduction in any medium, provided the original author and source are credited. 